\title{
Effect of dietary fat on the distribution of mucosal mass and cell proliferation along the small intestine
}

\author{
A P Jenkins, R P H Thompson
}

\begin{abstract}
This study investigated how substitution of long chain triglycerides for glucose in a mixed diet affects the overall small intestinal mucosal mass and the distribution of mucosal mass and cell proliferation along the small intestine. Four groups of eight female Wistar rats (180$200 \mathrm{~g}$ ) were isocalorically fed mixed diets containing the essential fatty acid rich oil Efamol substituted for glucose at concentrations of $1 \cdot 2 \%, 10 \%, 25 \%$, and $50 \%$ total calories for 20 to 23 days. The small intestine was divided into three equal length segments and whole gut weights, mucosal weights, protein and DNA determined. Cell proliferation was estimated from the two hour accumulation of vincristine arrested metaphases in microdissected crypts at points $\mathbf{0 \%}$, $17 \%, 33 \%, 50 \%, 66 \%$, and $100 \%$ small intestinal length. There were no differences between groups in parameters of overall small intestinal or distal segment mucosal mass. With increasing levels of fat, however, there was a significant trend for the mucosal mass of the proximal segment to fall and that of the middle segment to rise. The pattern of two hour metaphase accumulation reflected these changes. These regional changes in mucosal mass and cell proliferation may reflect differences in the sites of absorption of fat and glucose.
\end{abstract}

A proximal to distal descending gradient of mucosal mass along the small intestine has been described in the fed state. ${ }^{12}$ This might result from a corresponding gradient of luminal trophic factors. Altmann ${ }^{3}$ suggested that pancreaticobiliary secretions might provide such a trophic stimulus, but the presence of food within the small intestinal lumen (luminal nutrition) can stimulate mucosal cell proliferation directly, ${ }^{+6}$ perhaps through the 'workload' of absorption. ${ }^{67}$ Thus greater availability of luminal nutrients proximally rather than distally could also account for the mucosal mass gradient.

If luminal nutrients stimulate mucosal cell proliferation maximally at their sites of absorption, the composition of diets could influence the small intestinal gradient of mucosal mass, depending on the sites where the constituent nutrients are absorbed. In favour of this, the elemental diet Vivonex produces atrophy that is most marked in the distal small intestine; ${ }^{2-8}$ in other words the gradient of mucosal mass is exaggerated. This could be because Vivonex is composed mainly of readily absorbed glucose polymers and amino acids and contains no dietary fibre; thus the diet would be well absorbed proximally with little reaching the distal small intestine. By contrast, we have shown that the gradient of mucosal mass in the proximal two thirds of the rat small intestine can be reduced by substituting long chain triglycerides for glucose in a diet. ${ }^{9}$ This might reflect more distal absorption of fat than of glucose. ${ }^{10} 11$

In our earlier study we also showed that long chain triglycerides had an overall trophic effect on the rat small intestinal mucosa compared with glucose. ${ }^{9}$ As the oil was not emulsified in the remainder of the liquid diet, however, it was administered in a separate phase and thus effectively as a bolus. We subsequently showed that bolus doses of long chain triglycerides were trophic to the small intestine compared with the same daily dose given as part of a mixed feed consumed over 24 hours, ${ }^{12}$ but it it still unclear whether long chain triglycerides in a mixed feed are enterotrophic compared with glucose:

In the current study increasing amounts of long chain triglycerides, given as the essential fatty acid rich oil Efamol, were substituted for glucose in four mixed diets. Detailed measurements were made of the effects of increasing dietary fat on the overall levels of small intestinal mucosal mass and on the distribution of mucosal mass and cell proliferation along the small intestine.

\section{Methods}

ANIMALS AND FEEDING

Four groups of eight female Wistar rats (180-200 g) were fed mixed powder diets containing differing amounts of Efamol (Scotia Pharmaceuticals Ltd, Guildford, Surrey, United Kingdom) substituted for glucose (Table I). The content of amino acids (Albumaid Complete, Scientific Hospital Supplies, Liverpool, United Kingdom) remained constant. All four diets were supplemented equally $(2 \cdot 24 \mathrm{~g} / 100 \mathrm{kcal})$ with a vitamin/mineral mixture (Special Diets Services Ltd, Stepfield, Essex, United Kingdom). The diets contained no fibre. The animals were housed individually in cages with wire bottoms and were allowed tap water ad libitum. The diets were delivered from low spillage glass containers $^{13}$ and the group of rats receiving 50\% dietary calories as Efamol was allowed to feed $a d$ libitum. The food intake for this group was measured daily and the average energy intake per rat calculated. This calorific value of food was then given to each rat of the other three groups

TABLE I Composition of diets (\% total calories)

\begin{tabular}{lllll}
\hline Efamol & $1 \cdot 2 \%$ & $10 \%$ & $25 \%$ & $50 \%$ \\
Glucose & $83 \cdot 8 \%$ & $75 \%$ & $60 \%$ & $35 \%$ \\
Amino acids & $15 \%$ & $15 \%$ & $15 \%$ & $15 \%$ \\
\hline
\end{tabular}

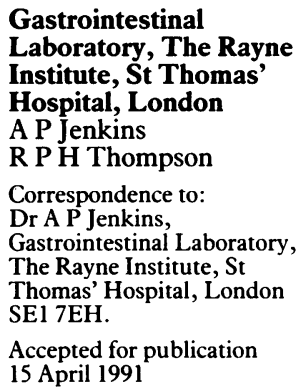


for the subsequent 24 hours. Thus, the energy intakes of the groups were matched, although the animals were not individually pair fed.

\section{SAMPLING AND MEASUREMENTS}

Two animals from each group were killed by overdose of halothane anaesthetic between 0900 and 1300 hours on each of four consecutive days, 20 to 23 days after the start of the experiment. Food was withdrawn at 2300 hours the day before being killed and the animals were given intraperitoneal vincristine sulphate (Lilly France SA, Fegersheim, France; $1.0 \mathrm{mg} / \mathrm{kg}$ ) exactly two hours before being killed in order to measure crypt cell proliferation from the accumulation of vincristine arrested metaphases.

The small intestine, including part of the duodenum, was removed from the duodenal papilla to the ileocaecal valve. Its length was measured under $10 \mathrm{~g}$ vertical tension and the intestine divided into three equal length segments (proximal, middle, and distal). One centimetre samples for subsequent counting of arrested metaphases were taken from the proximal end, midpoint and distal end of the proximal segment, from the mid point and distal end of the middle segment and from the distal end of the distal segment - that is, at distances $0 \%, 17 \%$, $33 \%, 50 \%, 66 \%$, and $100 \%$ along the removed small intestine. The segments of small intestine were then flushed with ice cold $0.9 \%$ sodium chloride solution followed by air. Adherent fragments of mesentery were carefully dissected free and the segments weighed to give an estimate of whole gut weight. The mucosa was gently blotted with tissue paper, scraped off with a glass slide, weighed and frozen at $-20^{\circ} \mathrm{C}$ for subsequent determination of protein and DNA content. ${ }^{1415}$

The $1 \mathrm{~cm}$ samples of small intestine were slit open longitudinally and orientated mucosal side uppermost on small pieces of card. They were fixed in Carnoy's fluid and stored in 70\% ethanol (v/v). A portion of each sample was bulk stained using the Feulgen reaction, the two hour accumulation of vincristine arrested metaphases counted in 10 randomly selected, microdissected crypts $^{16}$ and the mean calculated.

TABLE II Diet (\% Efamol)

\begin{tabular}{llllll}
\hline & $1 \cdot 2 \%$ & $10 \%$ & $25 \%$ & $50 \%$ & One-way ANOVA \\
\hline Final rat weight (g) & $210 \cdot 9$ & $210 \cdot 4$ & $210 \cdot 3$ & $207 \cdot 6$ & NS \\
Rat weight gain (g) & $(3 \cdot 1)$ & $(3 \cdot 6)$ & $(2 \cdot 6)$ & $(4 \cdot 0)$ & NS \\
Small intestinal & $19 \cdot 9$ & $22 \cdot 1$ & $22 \cdot 0$ & $20 \cdot 0$ & (2.5) \\
length (cm) & $108 \cdot 4$ & $(3 \cdot 3)$ & $(1 \cdot 7)$ & $(2 \cdot 5)$ & NS \\
\hline
\end{tabular}

TABLE III Diet (\% Efamol)

\begin{tabular}{lcllll}
\hline & $1 \cdot 2 \%$ & $10 \%$ & $25 \%$ & $50 \%$ & One-way ANOVA \\
\hline Overall whole gut & $42 \cdot 24$ & $42 \cdot 05$ & $42 \cdot 28$ & $41 \cdot 86$ & NS \\
weight $(\mathrm{mg} / \mathrm{cm})$ & $(0 \cdot 93)$ & $(1 \cdot 83)$ & $(1 \cdot 11)$ & $(1 \cdot 19)$ & \\
Overall mucosal & $10 \cdot 69$ & $11 \cdot 43$ & $10 \cdot 80$ & $11 \cdot 03$ & $\mathrm{NS}$ \\
$\begin{array}{c}\text { weight }(\mathrm{mg} / \mathrm{cm}) \\
\text { Overall mucosal }\end{array}$ & $(0 \cdot 46)$ & $(1 \cdot 30)$ & $(0 \cdot 49)$ & $(0 \cdot 64)$ & \\
protein $(\mathrm{mg} / \mathrm{cm})$ & $1 \cdot 39$ & $1 \cdot 83$ & $1 \cdot 45$ & $1 \cdot 61$ & $\mathrm{NS}$ \\
Overall mucosal & $(0 \cdot 06)$ & $(0 \cdot 20)$ & $(0 \cdot 09)$ & $(0 \cdot 12)$ & \\
DNA $(\mu \mathrm{g} / \mathrm{cm})$ & $106 \cdot 75$ & $113 \cdot 25$ & $114 \cdot 75$ & $110 \cdot 27$ & $\mathrm{NS}$ \\
\hline
\end{tabular}

\section{STATISTICAL ANALYSIS}

Between group comparisons of rat weight gain, small intestinal length, overall small intestinal whole gut weight, mucosal weight, and mucosal protein and DNA were made using one-way analysis of variance.

The effects of diet and overall small intestinal mass on individual segment mass parameters were analysed using multiple linear regression.

The changes in two hour metaphase accumulation along the small intestine were assessed using repeated measures analysis of variance. ${ }^{17}$

Results are expressed as means, standard error of the mean (SEM).

\section{Results}

The mean daily intake per rat was $53.7 \mathrm{kcal}$ and there was no significant difference between the groups in weight gain and final body weight (Table II). Small intestinal length did not differ significantly between the groups (Table II).

There were no significant differences between the groups in overall small intestinal whole gut weight, mucosal weight and mucosal protein and DNA (Table III).

Figure 1 shows the segment whole gut weight and mucosal weights with the three segments plotted together for each diet. As the level of fat in the diet increased, the gradient of weights between the proximal and middle segments was reduced and eventually reversed at Efamol levels of $50 \%$ total calories. Similar changes were found for mucosal protein and DNA (Figure 2), although for DNA reversal of the gradient first occurred at Efamol levels of $25 \%$ total calories.

Figures 3 and 4 show how the changes in mass
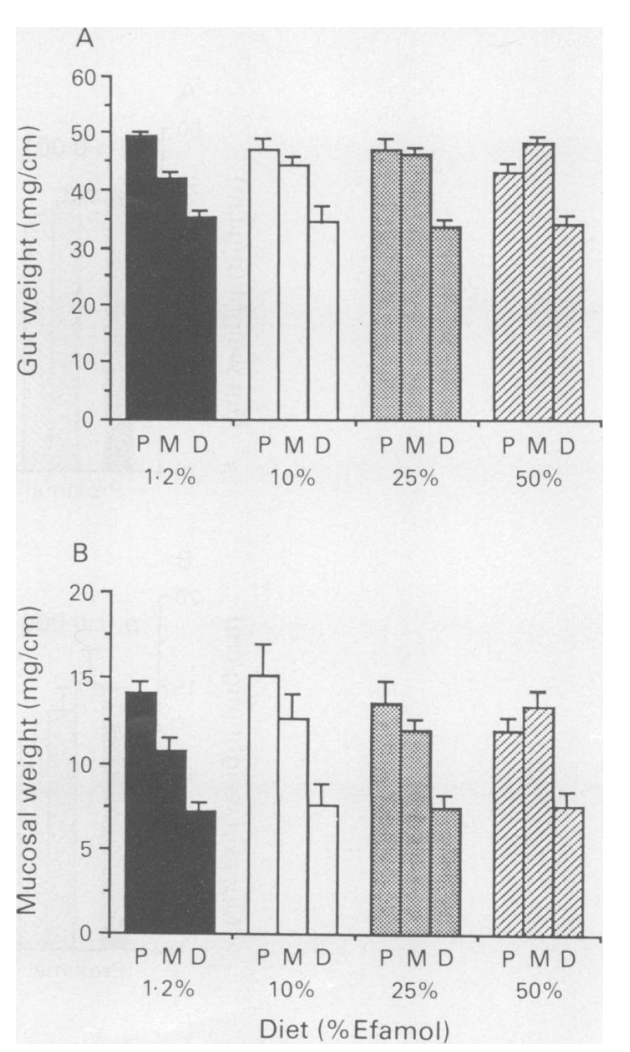

Figure 1: Effect of diet on the gradients of $(a)$ whole gut weight and $(b)$ mucosal weight along the small intestine. $P=$ proximal,$M=$ middle, $D=$ distal segment. 
gradients occur by plotting the values for each segment together. As the level of fat increased there was a tendency for proximal segment mass to fall and for middle segment mass to rise, the
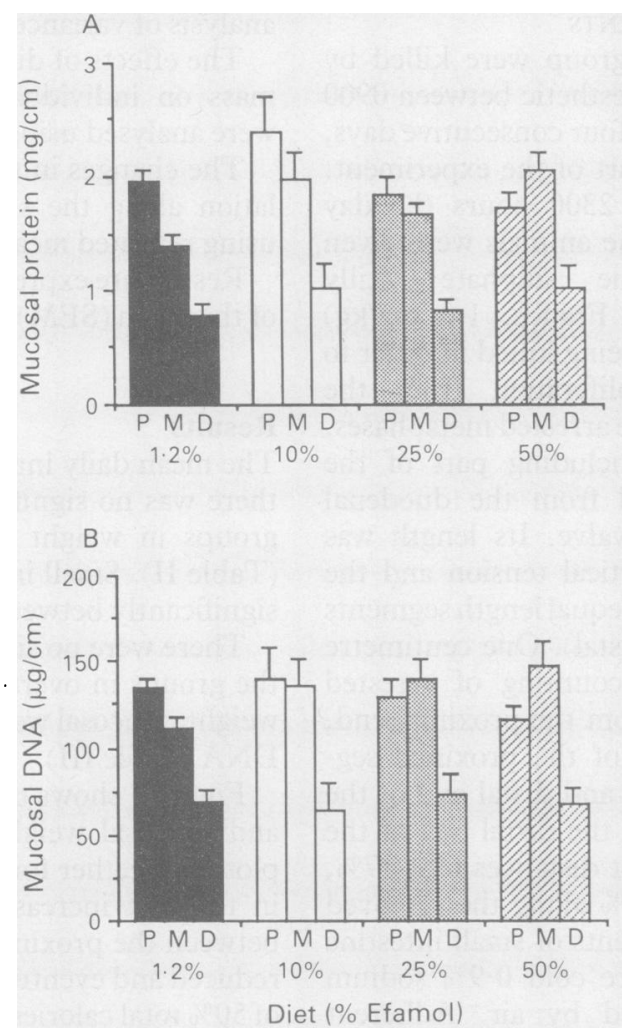

Figure 2: Effect of diet on the gradients of (a) mucosal protein and $(b)$ mucosal DNA along the small intestine. $P=$ proximal, $M=$ middle, $D=$ distal segment.

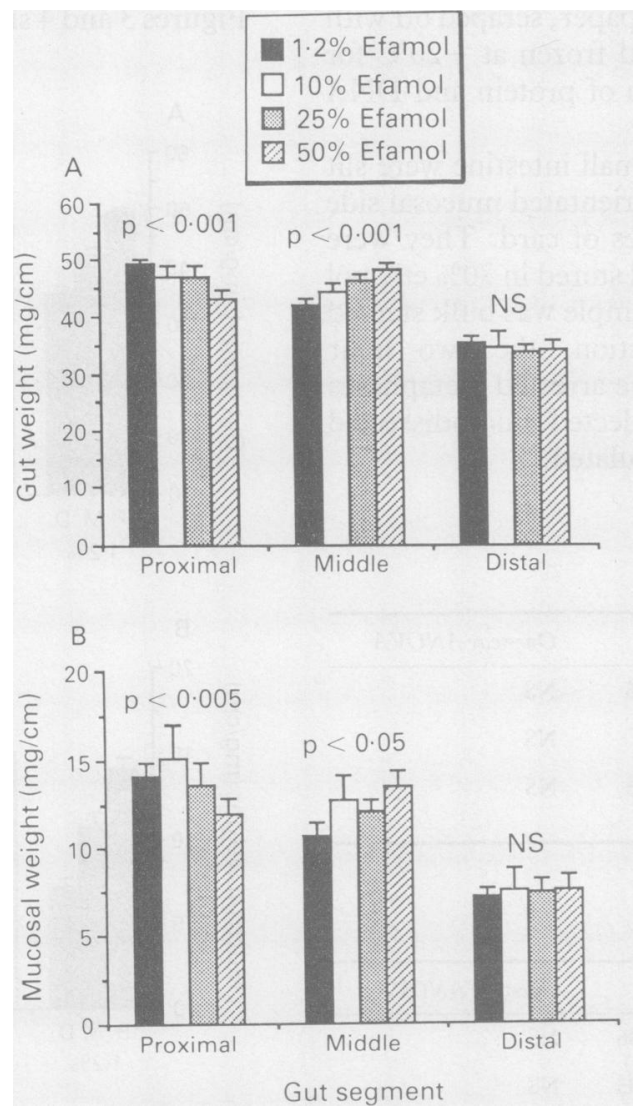

Figure 3: Changes in (a) segment whole gut weight and (b) segment mucosal weight with diet. Significance values refer to the correlation of segment mass with diet as assessed by multiple linear regression. distal segment not changing between diets. The mass of each segment may be determined not only by diet, however, but also by overall small intestinal mass and even small, statistically nonsignificant variations in overall small intestinal mass could produce effects that obscure trends relating segment mass to diet. Therefore, multiple linear regression was carried out to distinguish the effects of diet from those of overall small intestinal mass, and this test confirmed that levels of all parameters of proximal and middle segment mass were significantly correlated with diet (Fig 3, 4). Multiple regression also confirmed that there was a significant correlation between the mass of each segment and overall small intestinal mass $(\mathrm{p}<0.001$ for all parameters of mass). This may explain why the mean values of mucosal weight and protein for the group receiving $10 \%$ Efamol appear to fall outside the trend of changes of proximal and middle segment mucosal mass with diet (Fig $3 b$, $4 a)$; this group had somewhat higher levels of overall mucosal weight and protein than did the other groups (Table III), presumably from chance variation.

A further way to correct for the effects of the minor variations in overall intestinal mass on segment mass is to express the mass of each segment as a percentage of the total small intestinal mass. The mucosal mass parameters plotted in this way are shown in Figure 5. This shows even more clearly that with increasing levels of dietary fat the proportion of total mass in the proximal segment fell, while that in the middle segment rose.

The two hour metaphase accumulations
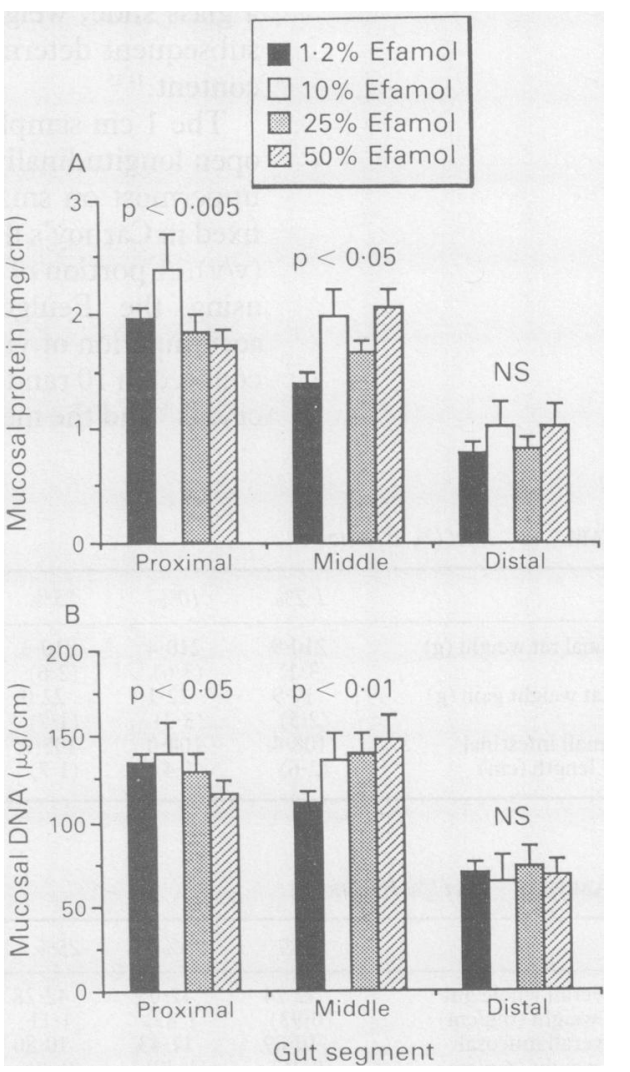

Figure 4: Changes in (a) segment mucosal protein and (b) segment mucosal DNA with diet. Significance values refer to the correlation of segment mass with diet as assessed by multiple linear regression. 


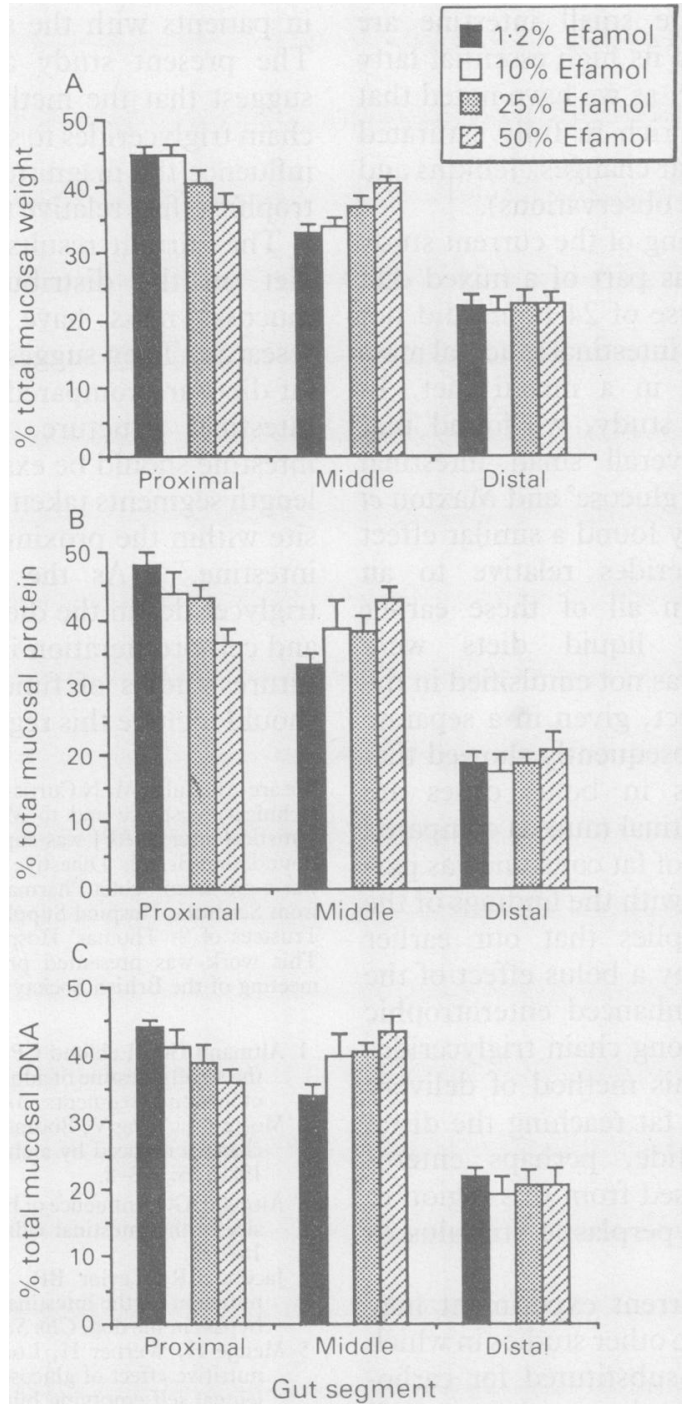

Figure 5: Effect of diet on the percentage of the total mucosal mass contributed by each segment: $(a)$ mucosal weight, (b) mucosal protein, (c) mucosal DNA.

reflected the mucosal mass measurements (Fig 6). At the proximal small intestinal distances $(0 \%$ and $17 \%$ ) cell proliferation was highest for the $1 \cdot 2 \%$ Efamol diet and decreased as the level of fat increased. In contrast, at 33\% distance cell proliferation was lowest for the $1 \cdot 2 \%$ Efamol diet and increased with increasing fat levels. There was a similar pattern at $50 \%$, although the value for $25 \%$ Efamol fell outside the trend. At $66 \%$ and $100 \%$ there were no trends discernible. Repeated measures analysis of variance con-

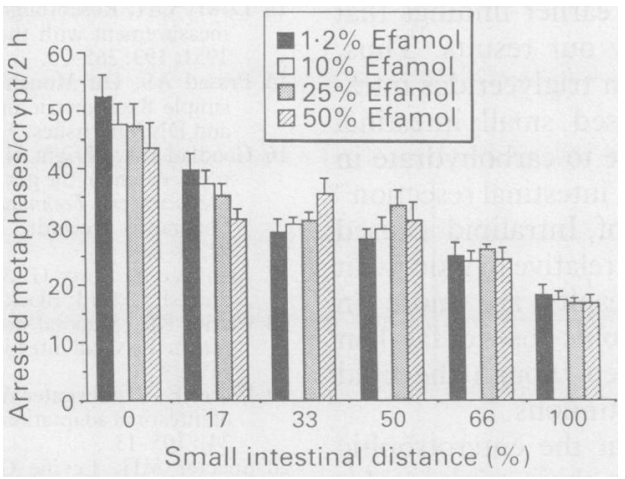

Figure 6: Effect of diet on two hour metaphase accumulation. firmed that the effect of small intestinal distance on metaphase accumulation differed between $\operatorname{diets}(\mathrm{p}<0.01)$.

\section{Discussion}

The results confirm that the gradient of mucosal mass along the small intestine is strongly influenced by diet. Isocalorically substituting increased amounts of Efamol for glucose as part of a mixed diet caused a reduction and eventual reversal of the mucosal mass gradient between the proximal and middle segments. This was caused, in effect, by a 'redistribution' of mucosal mass from the proximal small intestinal segment to the middle small intestinal segment, the distal segment and overall mucosal mass not changing significantly between diets. The crypt cell production rate has been stated to be constant along the length of the small intestine, ${ }^{18}$ but the data on two hour metaphase accumulation in the current study show that the pattern of cell proliferation along the small intestine also varies with diet.

A possible explanation for the findings is that they reflect differing absorption sites for glucose and fat. Weser $e t a l^{19}$ showed that in rats maintained on total parenteral nutrition intragastric infusion of glucose increased mucosal mass proximally in the small intestine. Infusion of glucose into the mid small bowel, however, produced maximum levels of mucosal mass at the site of infusion. Moreover, including phlorizin, an inhibitor of glucose absorption, in the test solution caused the peak of mucosal mass to shift caudally along the small intestine. These results strongly suggest that luminal nutrients stimulate mucosal cell proliferation maximally at their site of absorption. This might be caused by a local direct trophic effect of luminal nutrients, perhaps related to the 'workload' of absorption. ${ }^{67}$ Such a local effect of luminal nutrients may occur independently of, or in addition to, more generalised indirect enterotrophic actions that may perhaps be mediated by release of a trophic gut peptide. ${ }^{561920}$

The changes in the distribution of small intestinal mucosal mass and cell proliferation with diet are compatible with differences known to exist between the principal absorption sites of glucose and fat. Orally ingested glucose is almost completely absorbed in the upper small intestine in man and in rats. ${ }^{1021}$ In man, the site of fat absorption is distal to that of glucose $e^{21}$ and in the rat, after intraduodenal infusion of triolein, maximum accumulation of fat in the intestinal wall occurs in the distal jejunum and proximal ileum. ${ }^{22}$ In keeping with these findings, the higher the glucose content of the diet in the present study the more did the distribution of mucosal mass favour the proximal segment, and the greater was the level of cell proliferation at $0 \%$ and $17 \%$ along the small intestine. As the level of glucose in the diet decreased and that of fat increased, there was a tendency for proximal segment mass to fall and middle segment mass to rise and this was associated with a trend for increased levels of metaphase accumulation at $33 \%$ and $50 \%$ along the small intestine.

The effects of Efamol on the distribution of 
mucosal mass along the small intestine are unlikely to be because of its high essential fatty acid content, specifically, as we have noted that long chain triglycerides rich in fully saturated fatty acids produce similar changes (Jenkins and Thompson, unpublished observations).

The second main finding of the current study was that Efamol given as part of a mixed diet consumed over the course of 24 hours did not increase the overall small intestinal mucosal mass compared with glucose in a mixed diet. In contrast, in our earlier study, we found that Efamol did increase overall small intestinal mucosal mass relative to glucose ${ }^{9}$ and Maxton et $a l^{232+}$ from this laboratory found a similar effect for long chain triglycerides relative to an elemental diet alone. In all of these earlier experiments, however, liquid diets were administered and, as it was not emulsified in the diet, the oil was, in effect, given in a separate phase as a bolus. We subsequently showed that long chain triglycerides in bolus doses are trophic to the small intestinal mucosa compared with the same daily dose of fat consumed as part of a mixed feed. ${ }^{12}$ Taken with the findings of the current study, this implies that our earlier results ${ }^{9324}$ were caused by a bolus effect of the administered oil. The enhanced enterotrophic effect of bolus doses of long chain triglycerides might be explained if this method of delivery increased the amount of fat reaching the distal ileum. A trophic peptide, perhaps enteroglucagon, could be released from this region to provide an additional hyperplastic stimulus to the small intestine. ${ }^{25} 26$

The results of the current experiment may explain the findings of two other studies in which long chain triglycerides substituted for carbohydrate actually appeared to cause small intestinal mucosal hypoplasia by reducing parameters of jejunal mucosal mass. ${ }^{27}{ }^{28}$ In these experiments the fat was administered as part of a mixed diet. Our present results suggest that, under these conditions, the long chain triglycerides would have caused no overall trophic effect compared with carbohydrate, although they would have produced a 'redistribution' of mucosal mass away from the proximal jejunum to the mid small intestine. No measurements were made of mid small intestine mass in those two studies, ${ }^{27} 28$ and, without this information, the observations from the proximal jejunum would have incorrectly suggested that high fat diets cause mucosal atrophy relative to carbohydrate.

There remain, however, earlier findings that are not easily explained by our results. Thus, direct infusion of long chain triglycerides intragastrically caused generalised small intestinal mucosal hyperplasia relative to carbohydrate in animals after proximal small intestinal resection ${ }^{29}$ and intrajejunal infusion of Intralipid caused jejunal mucosal hyperplasia relative to glucose in intact animals. ${ }^{30}$ These results are more in keeping with the effects of bolus doses of fat than with the current study, even though the lipid infusions were slow and continuous.

It has been proposed that the enterotrophic effects of diets rich in long chain triglycerides may be useful in enhancing the adaptive response in patients with the short bowel syndrome..$^{2329}$ The present study and our earlier results ${ }^{912}$ suggest that the method of administering long chain triglycerides to such patients may critically influence the magnitude of their overall enterotrophic effect relative to other nutrients.

The current results describing the effects of diet on the distribution of small intestinal mucosal mass have implications for future research. They suggest that when high and low fat diets are compared for their effects on small intestinal structure, the whole of the small intestine should be examined and not just equal length segments taken from the same anatomical site within the proximal two thirds of the small intestine. ${ }^{27} 28$ As the presence of long chain triglycerides in the diet increased mucosal mass and cell proliferation in the mid small intestine, future studies of function after high fat diets should include this region of the intestine.

We are grateful to Mr N Curtis-Davis and Miss M-L Heffernan for technical assistance and to $\mathrm{Mr} \mathrm{R}$ Morris and $\mathrm{Mr} \mathrm{N}$ Taub for statistical advice. APJ was supported by a Nutritional Research Foundation/British Digestive Foundation Fellowship. Efamol was a gift from Scotia Pharmaceuticals Ltd and Albumaid a gift from Scientific Hospital Supplies. We are grateful to the Special Trustees of St Thomas' Hospital for their continuing support. This work was presented previously in abstract form at the This work was presented previously in abstract form at the
meeting of the British Society of Gastroenterology, March 1990.

1 Altmann GG, Leblond CP. Factors influencing villus size in the small intestine of adult rats, as revealed by transposition the small intestine of adult rats, as revealed by transpos

2 Morin CL, Ling V, Bourassa D. Small intestinal and colonic changes induced by a chemically defined diet. Dig Dis $S c i$ 1980; 25: 123-8.

3 Altmann GG. Influence of bile and pancreatic secretions on the size of the intestinal villi in the rat. Am f Anat 1971; 132: 167-78.

4 Jacobs LR, Taylor BR, Dowling RH. Effect of luminal nutrition on the intestinal adaptation following Thiry-Vella bypass in the dog. Clin Sci Mol Med 1975; 49: 26.

5 Menge $\mathrm{H}$, Werner $\mathrm{H}$, Lorenz-Meyer $\mathrm{H}$, Riecken EO. The nutritive effect of glucose on the structure and function of jejunal self-emptying blind loops in the rat. Gut 1975; 16: jejunal.

6 Clarke RM. "Luminal nutrition" versus "functional workload" as controllers of mucosal morphology and epithelial replacement in the rat small intestine. Digestion 1977; 15: 411-24

7 Richter GC, Levine GM, Shiau Y-F. Effects of luminal glucose versus non-nutritive infusates on jejunal mass and absorption in the rat. Gastroenterology 1983; 85: 1105-12.

8 Maxton DG, Cynk EU, Thompson RPH. Small intestinal response to "elemental" and "complete" liquid feeds in the rat; effect of dietary bulk. Gut 1987; 28: 688-93.

9 Jenkins AP, Thompson RPH. Trophic effect of Efamol on the rat small-intestinal mucosa. Clin Sci 1989; 77: 555-9.

10 Reynell PC, Spray GH. The simultaneous measurement of absorption and transit in the gastro-intestinal tract of the rat. absorption and transit in the gastro-in

11 Booth CC, Read AE, Jones E. Studies on the site of fat absorption. 1. The sites of absorption of increasing doses of 131I-labelled triolein in the rat. Gut 1961; 2: 23-31

12 Jenkins AP, Thompson RPH. The effect of bolus doses of fat on small intestinal mucosal cell proliferation. Gut 1989; 30: A 1509 .

13 Senapati A, Johnson C, Brown IMH, Thompson RPH. A method to reduce spillage in pair-fed rats. Anim Technol 1984; 35: $123-4$

14 Lowry OH, Rosebrough NJ, Farr AL, Randall RS. Protein measurement with the Folin-phenol reagent. $\mathcal{F}$ Biol Chem 1951; 193: 265-75.

15 Prasad AS, Du Mouchelle E, Koniuch D, Oberleas D. A simple fluorometric method for the determnation of RNA and DNA in tissues. F Lab Clin Med 1972; 80: 598-602.

16 Goodlad RA, Wright NA. Quantitative studies on epithelial replacement in the gut. In: Titchen TA, ed. Techniques in the life sciences. Techniques in digestive physiology. Vol P2. Shannon, Ireland: Elsevier Biomedical Press, 1982: 212/1-23.

17 Armitage P, Berry G. Statistical methods in medical research. 2nd ed. Oxford: Blackwell, 1987.

18 Clarke RF. Mucosal architecture and epithelial production rate in the small intestine of the albino rat. $\mathcal{F}$ Anat $1970 ; 107$ 519-29.

19 Weser E, Vandeventer A, Tawil T. Non-hormonal regulation of intestinal adaptation. Scan $\mathcal{F}$ Gastroenterol 1982; 17 (suppl 74): 105-13.

20 Spector MH, Levine GM, Deren JJ. Direct and indirect effects of dextrose and amino acids on gut mass. Gastroenterology 1977; 72: 706-10. 
21 Johansson C, Lagerlof HO, Ekelund K, Kulsdom N, Larsson I, Nylind B. Studies of gastrointestinal interactions III Determination of gastric secretion and evacuation, biliar and pancreatic secretion, intestinal absorption, intestina transit time and flow of water in man. Scand $\mathcal{F}$ Gastroenterol 1972; 7: 489-99.

22 Clark SB, Lawergen B, Martin JV. Regional intestinal absorptive capacities for triolein: an alternative to markers. $A m \mathcal{Y}$ Physiol 1973; 225: 574-85.

23 Maxton DG, Cynk EU, Jenkins AP, Thompson RPH Effect of dietary fat on the small intestinal mucosa. Gut 1989; 30: 1252-5.

24 Maxton DG, Cynk EU, Thompsun RPH. Promotion of growth of the small intestine by dietary essential fatty acids. Eur f Gastroenterol Hepatol 1990; 2: 131-6.

25 Spiller RC, Trotman IF, Adrian TE, Bloom SR, Misiewicz JJ, Silk DBA. Further characterisation of the "ileal brake" reflex in man - effect of ileal infusion of partial digests of fat, protein and starch on jejunal motility and release of neuro- tensin, enteroglucagon and peptide YY. Gut 1988; 29: 1042 51

26 Bloom SR, Polak JM. Enteroglucagon and the gut hormone profile of intestinal adaptation. In: Robinson JWL, Dowling RH, Riecken EO, eds. Mechanisms of intestinal adaptation. Lancaster: MTP Press, 1982: 189-98.

27 Jacobs LR. Effect of short-term dietary fat on cell growth in the rat gastrointestinal mucosa and pancreas. $\mathrm{Am} \mathrm{FClin} \mathrm{Nutr}$ 1983; 37: 361-7.

28 Thomson ABR, Mc Intyre Y, Macleod J, Keelan M. Dietary fat content influences uptake of hexoses and lipids into rabbit jejunum following ileal resection. Digestion 1986; 35. 78-88.

29 Morin CL, Grey VL, Garofalo C. Influence of lipids on intestinal adaptation after resection. In: Robinson JWL, Dowling RH, Riecken EO, eds. Mechanisms of intestinal adaptation. Lancaster: MTP Press, 1982: 175-84.

30 Weinberg LM, Pusateri JP, Levine GM. Comparison of different caloric substrates on intestinal adaptation in the rat. Gastroenterology 1989; 96: $151+20$. 